\title{
Design Heuristics in Engineering Concept Generation
}

\author{
Shanna R. Daly, ${ }^{a}$ Seda Yilmaz,,${ }^{b}$ James L. Christian, ${ }^{c}$ \\ COLLEEN M. SEIFERT, ${ }^{a}$ AND RICHARD GONZALEZ ${ }^{a}$ \\ ${ }^{a}$ University of Michigan, ${ }^{b}$ Iowa State University, \\ 'Massachusetts Institute of Technology
}

\begin{abstract}
BACKGROUND
Innovation in design depends on successful concept generation. The ideation stage of design is intended to produce multiple, varied concepts from which to develop and choose. Often, instruction on idea generation methods is not offered in engineering classes; however, when taught, it is commonly through techniques like brainstorming, which lacks specific ways to generate designs. Further, existing ideation strategies are not based on evidence from designers or rigorous testing through empirical studies.
\end{abstract}

\section{PURPOSE}

This study investigated how engineering students and practitioners generated ideas. We focused on how designers used product characteristics to define concepts, and how previous concepts were transformed into new solutions by modifying their characteristics. Our methodology is based on our previous work identifying Design Heuristics in engineering solutions, defined as cognitive prompts that facilitate exploration of multiple designs during concept generation.

\section{METHOD}

Think-aloud recordings and concept sketches were collected from 36 engineering students and practitioners (with varying levels of experience) as they generated ideas for a novel design task in a laboratory setting. These data, along with retrospective interviews, were analyzed for the ideation strategies evident in the participants' solutions.

\section{RESULTS}

This study revealed evidence for over 60 strategies for concept generation during the ideation stage. Participants generated novel concepts and proposed concept modifications, and specific Design Heuristics were observed in their designs. The results suggest instruction on Design Heuristics can aid in effective idea generation.

\section{ConClusions}

This protocol study of engineering designers provides a collection of heuristics observed in practice that offers new methods for students and practitioners to explore design spaces. The Design Heuristics identified in this and previous work can potentially be learned and then incorporated into the practice of engineering students and practitioners.

\section{KEYWORDS}

concept generation, design approaches, Design Heuristics 


\section{INTRODUCTION}

One of the goals of the undergraduate engineering curriculum, as defined by ABET (ABET Board of Directors, 2011), is to support students' development of design skills. Additionally, numerous reports have called for engineering students to develop the ability to design innovative solutions to the increasingly complex problems in the world today (Duderstadt, 2008; Sheppard, Macatangay, Colby, \& Sullivan, 2009). While engineering design education has adopted project-based courses (Dym, Agogino, Eris, Frey, \& Leifer, 2005; Todd, Magleby, Sorensen, Swan, \& Anthony, 1995), research indicates challenges for students in learning to innovate. Students find it difficult to generate creative solutions (Ahmed, Wallace, \& Blessing, 2003; Ball, Evans, \& Dennis, 1994; Cross, 2001; Rowe, 1987; Ullman, Dietterich, \& Stauffer, 1988), and engineering educators find it difficult to teach students how to think innovatively (Grasso, Burkins, Helble, \& Martinelli, 2008; Klukken, Parsons, \& Columbus, 1997; Pappas \& Pappas, 2003; Richards, 1998). Teachable strategies for idea generation could play a significant role in building innovation skills in engineers and preparing them for the Grand Challenges for Engineering (National Academy of Engineering, n.d.) they will face as practitioners.

Creativity and innovation are defined in multiple ways, but for present purposes, we define a creative idea as one that is considered both novel and appropriate (Amabile, 1996; Torrance, 1962; Treffinger, Young, Shelby, \& Shepardson, 2002). Successful implementations of creative ideas produce innovations. Opportunities for creative ideas exist throughout the design process; however, the concept generation (or ideation) phase of the design process is a key step for the emergence of creative ideas (Cropley, 2006; Harvard Business School Press, 2003). Concept generation becomes the foundation for the development of a final product and serves as a guide for product research, feedback from stakeholders, and testing and experimentation on prototypes. Because innovation often hinges on a successful concept generation phase, it is imperative to understand how ideas are generated and what techniques can facilitate exploration of design solutions.

Ideally, the ideation phase would result in a candidate set of designs that are varied in nature, representing a wide variety of possible solutions. By considering a diverse set of potential concepts, the designer is more likely to come across novel and innovative solutions (Brophy, 2001; Liu \& Bligh, 2003). However, engineering designers often fail to consider multiple designs and become focused on specific options early in the design process. This tendency, termed fixation, prematurely limits the variety of designs considered (Cross, 2001; Janssen \& Smith, 1991; Purcell \& Gero, 1996). When engineers are in the ideation phase, it is unclear how they go about generating new concepts and what strategies they use to introduce variations in their designs.

This study sought to explore how engineers generated varied designs and to capture empirical evidence of what successful designers do to create ideas. We report the outcomes of a study in which 36 engineering students and practitioners worked individually to generate creative ideas for a design task. Our focus was on how these engineers generated design solutions as well as on how they introduced variation to form new solutions. Our empirical study of ideation is based on our previous studies of strategy use in the ideation phase (Daly, Yilmaz, Seifert, \& Gonzalez, 2010; Yilmaz, Daly, Seifert, \& Gonzalez, 2010; Yilmaz \& Seifert, 2009, 2010, 2011; Yilmaz, Seifert, Christian, Daly, \& Gonzalez, 2012; Yilmaz, Seifert, \& Gonzalez, 2010). Starting with the collection of these new protocols, we set out to determine how students and practicing engineers approached ideation and whether they made use of the Design Heuristics ideation strategy and any other ideation 
methods. We developed a method for extracting idea generation strategies from the observed protocols and identified a specific set of strategies, called Design Heuristics.

This study is situated in a larger project for which the long-term goals include (1) to develop a collection of Design Heuristics that have been shown across a variety of design contexts to support creative and diverse thinking in concept generation, (2) to examine patterns of Design Heuristics use, i.e., what strategies designers often use together and what strategies lead toward particular types of solutions, and (3) to compare design outcomes developed with Design Heuristics to design outcomes developed with other idea generation techniques.

Identifying how concept generation is accomplished successfully can help us to develop educational materials to assist engineers. The identification of successful design strategies can facilitate ideation skill development, which, in turn, can support innovation in engineering.

\section{BACKGROUND}

Ideation in design is most successful, and most likely to lead to innovation, when multiple and diverse concepts are generated (Akin, 1990; Atman, Chimka, Bursic, \& Nachtmann, 1999; Brophy, 2001; Cross, 2001; Liu \& Bligh, 2003). Diverse idea generation is defined as a process that visits many different areas of the "design solution space" (following the "problem space" of Newell and Simon, 1972; Daly, Christian, Yilmaz, Seifert, \& Gonzalez, 2012). In the space of all feasible solutions, some areas are readily found because those types of solutions already exist or involve simple combinations of known features or elements. However, many ideas are more difficult to generate because they are not obvious, but do exist in the space of possible solutions.

Novice designers often have difficulty generating a variety of diverse concepts during concept generation, and they appear hesitant in considering multiple ideas (Cross, 2001). When an individual designer (or team of designers) creates a potential solution, they often continue pursuing this single idea at the expense of exploring other alternatives. A number of studies have investigated this premature closure of the search process, defined as fixation (Cross, 2001; Jansson \& Smith, 1991; Purcell \& Gero, 1996; Linsey, Tseng, Fu, Cagan, Wood, \& Schunn, 2010). Niku (2009) described some of the reasons for fixation, including holding false assumptions, abiding by nonexistent limitations, feeling overwhelmed, having incomplete or partial information, and following improper methods of solution.

Novice engineering designers also have a sense of attachment to early solution ideas and hang onto concepts even when they realize they may be extremely difficult to pursue or have major flaws (Ball et al., 1994; Rowe, 1987; Ullman et al., 1988). Atman et al. (1999) found that freshman designers generated fewer solutions than senior designers, which suggests that as expertise develops, designers improve at diverging during concept generation. However, studies have shown that even years of professional experience were not enough to avoid fixation (Jansen \& Smith, 1991; Purcell, Williams, Gero, \& Colbron, 1993; Purcell \& Gero, 1996; Smith, 1995). For example, in studies of advanced undergraduates in engineering, Purcell et al. (1993) suggested that the complexity of examples within a domain might focus attention on specific constraints, leading to fixation. Thus, techniques to help combat this challenge in design may be applicable across levels of expertise.

In addition, engineering students may lack knowledge of successful strategies to help them explore other solutions. Previous studies have shown they lack skills to help 
them generate more concepts that are different from their initial ideas (Cross, 2001; Sachs, 1999). When students do create multiple concepts, they are often minor variations on the same idea (Rowe, 1987). As a result, engineering students generate an impoverished set of concept options for moving forward in the design process.

To combat these challenges, theorists have proposed a number of idea generation techniques and approaches. For example, one proposal to support divergent thinking throughout design is divergent inquiry: using specific types of questions to guide divergent activity (Eris, 2004). Table 1 lists popular suggested ideation techniques; see Smith (1998) for a more complete listing.

These ideation methods vary in their focus, specificity, and usability. For example, TRIZ focuses on refinements of engineering mechanisms and design trade-offs that arise in the implementation phase of the design process. Other techniques, such as brainstorming, are aimed at ideation starting from a blank slate (without any initial concepts). Brainstorming provides three very general guidelines: namely, suggest as many ideas as possible, do not evaluate while generating, and build off of others' ideas. However, brainstorming does not provide specific directions for creating ideas. SCAMPER offers more specific guidelines (e.g., combine and modify). Other methods offer much more detail, but also require extensive training before use (e.g., Synectics, TRIZ, and SIT).

Only a few of these approaches have received any systematic empirical support. TRIZ was the result of a rigorous analysis of the outcomes of designs in the form of engineering patents awarded by the U.S. Patent Office (Altshuller, 1984). Though based on actual designs, a patent represents the outcome of hundreds of hours of design work rather than the initial stages of idea generation leading to that outcome. While engineers have been trained to use TRIZ to generate ideas, no scientific evidence has been collected that documents the use of TRIZ principles by untrained engineers. A prime motivation for the present study was to examine the ideation process in engineers as they worked on a single design task. By observing their work session, their methods for generating ideas can be discovered.

Analogical reasoning has been proposed as an effective idea generation technique in multiple studies within engineering. Studies of practicing engineering teams documented frequent use of analogies both within and across domains (Christensen \& Schunn, 2007, 2009; Dahl \& Moreau, 2002). Experimental studies showed the representation of a simple verbal analogy in memory affected its use in design innovation (Casakin, 2003; Linsey, Murphy, \& Markman, 2006). Though all designers were found to profit from visual analogies, reference to them (for example, a tree with exposed roots) was particularly helpful for novice designers (Casakin \& Goldschmidt, 1999). Further, Jin and Benami (2010) found that instruction to engineers that provided form, behavior, and exemplar analogies resulted in concepts based on the specific analogies provided. However, the meaningfulness and relevance of the specific analogy provided were overwhelmingly important to its successful use in design. This suggests that analogy is a very important source of ideas in design, but that the specific analogies used to prompt concepts matter (Holyoak \& Thagard, 1995). Thus, as a method for idea generation across design tasks, the use of analogy still requires the designer to generate an appropriate exemplar.

Both positive and negative results arise from team ideation methods such as brainstorming. Research has shown that as teams developed concepts, the quality of the concepts improved (Linsey et al., 2011) and that groups outperformed individuals 
TABLE 1

Example Concept Generation Techniques

\begin{tabular}{|c|c|}
\hline Technique & Description and resources \\
\hline Analogical thinking & $\begin{array}{l}\text { Transferring information from familiar instances to construct new ideas; } \\
\text { e.g., biomimicry } \\
\text { Casakin \& Goldschmidt, 1999; Finke, Ward, \& Smith, 1992; Holyoak } \\
\text { \&Thagard, 1995; Perkins, } 1997\end{array}$ \\
\hline Attribute listing & $\begin{array}{l}\text { Breaking a problem into pieces and addressing each problem attribute } \\
\text { separately } \\
\text { Morgan, } 1993\end{array}$ \\
\hline Brainstorming & $\begin{array}{l}\text { Group method of allowing naturally-occurring ideas to be shared without } \\
\text { judgment, and built upon by a team } \\
\text { Osborn, } 1953\end{array}$ \\
\hline Case-based reasoning & $\begin{array}{l}\text { Using examples of old designs to inspire the creation of new ones } \\
\text { Kolodner, 1993,1997; Kolodner \&Wills, 1993; Riesbeck \& Schank, } \\
1989\end{array}$ \\
\hline Forced connections & $\begin{array}{l}\text { Using an unrelated stimulus chosen at random, such as a word or an } \\
\text { image, as inspiration for design concepts } \\
\text { de Bono, 1975; Firestien, 1996; MacCrimmon \& Wagner, } 1994\end{array}$ \\
\hline IDEO cards & $\begin{array}{l}\text { Using prompts to suggest methods for gathering information about the } \\
\text { needs and wants of target users } \\
\text { IDEO, } 2002\end{array}$ \\
\hline Lateral thinking & $\begin{array}{l}\text { Generating a provocative or radical statement about the problem or } \\
\text { possible solution to push the designer towards more diverse ideas } \\
\text { de Bono, } 1975\end{array}$ \\
\hline Morphological analysis & $\begin{array}{l}\text { Listing properties and functions of a design solution and multiple options } \\
\text { for achieving each, then forming combinations to generate concepts } \\
\text { Allen, 1962; Zwicky, } 1969\end{array}$ \\
\hline SCAMPER & $\begin{array}{l}\text { Considering transformations to existing concepts of the following types: } \\
\text { Substitute, combine, adapt, modify, put to other purposes, eliminate, rearrange } \\
\text { Eberle, 1995; Osborn, } 1953\end{array}$ \\
\hline SIT & $\begin{array}{l}\text { Systematically trying to modify an existing concept using "idea provok- } \\
\text { ing" operators: Unification, multiplication, division, breaking symmetry, } \\
\text { and object removal } \\
\text { Horowitz, } 1999\end{array}$ \\
\hline Synectics & $\begin{array}{l}\text { Using analogies and metaphors as prompts to motivate joining together } \\
\text { different and unrelated elements } \\
\text { Gordon, } 1961\end{array}$ \\
\hline TRIZ & $\begin{array}{l}\text { Applying modifications to existing concepts by identifying contradictions } \\
\text { Altshuller, 1984; Terninko, Zusman, \& Zlotin, } 1998\end{array}$ \\
\hline Whack Pack & $\begin{array}{l}\text { Using prompts to identify habitual patterns, new information, and } \\
\text { techniques } \\
\text { von Oech, } 2010\end{array}$ \\
\hline
\end{tabular}

while developing ideas to solve problems (Collins \& Guetzkow, 1964; Laughlin, 2002). On the other hand, working on ideas individually can be more efficient than collaboration (Diehl \& Stroebe, 1987; Mullen, Johnson, \& Salas, 1991). In a study of engineers, brainstorming produced fewer ideas than the combined efforts of an 
equivalent number of individuals working alone (Lewis, Sadosky, \& Connoly, 1975). This effect is consistent among most studies focusing on Osborn's brainstorming (Mullen et al., 1991).

Other methods for ideation in Table 1 have been proposed along with many examples illustrating their use. However, little systematic evidence has been presented for their usefulness in engineering design. An exception is an approach to concept generation called Design Heuristics, which has focused on identifying the ideation strategies used by engineers as they solve design problems (Daly et al., 2010; Yilmaz, Daly, Seifert, \& Gonzalez, 2010; Yilmaz \& Seifert, 2010, 2011). Design Heuristics are defined as cognitive prompts that point designers towards exploration of design variations. They are intended to help engineering designers move through the space of possible concepts, guide them towards non-obvious ideas, and help them to generate multiple concepts that are different from one other. They are also intended to support designers who have become fixated and are struggling to generate more, and more different, concepts.

An example of a Design Heuristic is Apply an existing mechanism in a new way, which prompts the designer to take an existing product or component and incorporate it to function differently in the final product. For example, in designing a generator, the engineer may take an existing mechanism such as a bicycle and apply it as a power source. This one Design Heuristic can be applied repeatedly to generate other concepts (e.g., using a water bottle to squirt water and turn a wheel). Other Design Heuristics (e.g., Change direction of access) can be added and combined (placing the pedals in the air with the rider beneath) to produce a variety of novel ideas. The set of Design Heuristics identified in our prior empirical studies provides specific directions to assist designers in coming up with novel variations of ideas (Daly et al., 2010; Yilmaz, Daly, Seifert, \& Gonzalez, 2010; Yilmaz \& Seifert, 2010; 2011).

Most importantly, the Design Heuristics method is grounded in studies of designers. A study of award-winning product concepts identified characteristics that distinguished creative outcomes from existing products (Yilmaz \& Seifert, 2010; Yilmaz et al., 2012). A detailed investigation of over 400 consumer product concepts identified 40 Design Heuristics varying in functionality, form, and user interaction. Another study examined over 200 designs by a professional designer for a universal access bathroom in residential homes. Thirty-four new Design Heuristics were identified through analysis of sketches showing transitions from one concept to another over time (Yilmaz \& Seifert, 2011). A third study added data based on observing engineers as they worked on novel design problems (Daly et al., 2010). Based on their comments while sketching, the engineers' concept generation techniques were identified (Gero \& McNeill, 1998). These studies form the empirical basis of Design Heuristics, and we employed these findings in our analyses of the present study.

\section{RESEARCH DESIGN}

\section{Research Questions}

Three questions guided this study: How do engineering students and practitioners explore the design space during the initial idea generation phase of design? How do they use product features to generate potential design solutions? What methods do they apply to generate and transform ideas? 


\section{Participants}

We recruited individuals through informal networks including engineering students and practitioners from multiple institutions, workplaces, and professional conferences. A $\$ 5$ gift card was provided as a token of appreciation for participation in the study. Our larger project included a broader range of participants, including novice non-engineers and very experienced industrial designers. For this study, we selected the engineering students and practicing engineers from the larger project sample, producing a sample with a range in experience levels with engineering design. We selected this population in order to investigate ideation strategies across levels of engineering training.

The resulting sample of 36 participants is large for a qualitative think-aloud protocol (Atman \& Bursic, 1998), and offered observations of a wide range of idea generation approaches and solutions. Table 2 presents participant information, including gender, years of experience, and educational levels. Those considered first-year students were in their first year of an undergraduate program in engineering and had no design education experiences, although two participants had over five years of design experience outside an engineering classroom as part of their prior jobs. The next category includes second-, third-, and fourth-year engineering undergraduate students who had completed at least one design project as part of engineering coursework. Graduate students and practitioners, comprising the last two categories, had many design project experiences in the classroom and, for some of the graduate students and all of the practitioners, outside the classroom as well. Our intention was to include a range of experience so that naturally occurring strategies, along with methods developed through training and experience, could be observed.

\section{Data Collection}

Data collection involved laboratory sessions where individuals were presented with a design problem. They were asked to create concept sketches, and to think aloud as they worked (Ericsson \& Simon, 1980, 1993; Hannu \& Pallah, 2000; Gero \& McNeill, 1998). These previous studies indicated people are able to report the thoughts in mind without altering their thinking process. A retrospective interview followed, where participants were asked to describe their approaches to ideation, including how they generated each concept, how they moved from one concept to another, and any strategies they used. Participants all reported they were comfortable speaking during the concept generation task. The think-aloud methodology has been successful in previous studies of engineering design cognition (Akin \& Lin, 1995; Atman \& Bursic, 1998; Atman et al., 1999; Atman et al., 2007; Eckersley, 1988).

The design task was an open-ended, novel problem related to one of the Grand Challenges for Engineering (National Academy of Engineering, n.d.). The task included a small set of criteria and constraints to keep the problem as simple as possible. Participants were given the design task in written form, asked to begin working, and instructed to include labels and descriptions on their sketches. The design task was similar to solar problems used in engineering curricula at the college level:

Sunlight can be a practical source of alternative energy for everyday jobs, such as cooking. Simple reflection and absorption of sunlight can generate adequate heat for this purpose. Your challenge is to develop products that utilize sunlight for heating and cooking food. The products should be portable and made of inexpensive materials. It should be able to be used by individual families, and should be practical for adults to set up in a sunny spot. 
TABLE 2

Participants by Years of Experience in Engineering

\begin{tabular}{|c|c|c|c|}
\hline & Participant number & Gender & Years of experience \\
\hline \multirow{10}{*}{$\begin{array}{l}\text { First-year } \\
\text { students (10) }\end{array}$} & 1 & $\mathrm{M}$ & 0 \\
\hline & 2 & $\mathrm{~F}$ & 0 \\
\hline & 3 & $\mathrm{~F}$ & 0 \\
\hline & 4 & M & 0 \\
\hline & 5 & M & 0 \\
\hline & 6 & M & 1 \\
\hline & 7 & $\mathrm{~F}$ & 1 \\
\hline & 8 & M & 1 \\
\hline & 25 & M & 6 \\
\hline & 32 & M & 10 \\
\hline \multirow{12}{*}{$\begin{array}{l}\text { Second-, third-, and } \\
\text { fourth-year students } \\
\text { (12) }\end{array}$} & 9 & M & 1 \\
\hline & 10 & $\mathrm{~F}$ & 1 \\
\hline & 11 & M & 1 \\
\hline & 12 & $\mathrm{~F}$ & 1 \\
\hline & 13 & $\mathrm{~F}$ & 1 \\
\hline & 14 & $\mathrm{~F}$ & 1 \\
\hline & 15 & $\mathrm{~F}$ & 1 \\
\hline & 16 & M & 2 \\
\hline & 19 & M & 2 \\
\hline & 21 & M & 3 \\
\hline & 22 & M & 4 \\
\hline & 26 & M & 6 \\
\hline \multirow[t]{9}{*}{ Graduate students (9) } & 17 & M & 2 \\
\hline & 18 & M & 2 \\
\hline & 20 & $\mathrm{~F}$ & 2 \\
\hline & 23 & M & 4 \\
\hline & 24 & $\mathrm{~F}$ & 5 \\
\hline & 28 & M & 7 \\
\hline & 29 & M & 8 \\
\hline & 30 & M & 8 \\
\hline & 34 & M & 13 \\
\hline \multirow[t]{5}{*}{ Practitioners (5) } & 27 & M & 6 \\
\hline & 31 & $\mathrm{~F}$ & 9 \\
\hline & 33 & $\mathrm{~F}$ & 10 \\
\hline & 35 & $\mathrm{~F}$ & 17 \\
\hline & 36 & M & 31 \\
\hline
\end{tabular}


Note: Specific materials for a targeted temperature can be postponed to a later stage. Do not worry about the specific quantity of heat that can be generated. Please focus on conceptual designs. Please consider both the ways of capturing the light, and the structural variety of the concepts.

The instructions also prompted the engineers to generate as many different concepts as possible during the session:

Please draw as many concepts as you can on the papers provided to you. The concepts can be iterations of concepts you generate, or they can be entirely new ideas. Please try to use one page for each concept. Also, elaborate on each concept in writing, using labels and descriptions. Give specifics about what the concepts represent and how you came up with each idea. We want you to create concepts that are creative and appropriate.

Participants were given 25 minutes to generate ideas. Because we wanted participants to spend their time on concept generation, we added the following information to the session in writing after 10 minutes into the task:

\section{The Basic Principles of Transferring Solar Energy into Thermal Energy}

Concentrating sunlight: Using usually a mirror or some type of reflective metal to concentrate light and heat from the sun into a small area makes the energy more concentrated and therefore stronger.

Converting light to heat: Any black colored material will improve the effectiveness of turning light into heat, as black absorbs light.

Trapping heat: Once the light is absorbed and converted to heat, trapping the heat inside makes it possible to reach similar temperatures on cold and windy days as on hot days.

This additional information was intended to encourage participants to move past any desire for more specific technical information before generating concepts. Instead, they were encouraged to make assumptions about the technical feasibility of possible solutions. The ten-minute interval allowed participants to approach the problem first in their own way; then the technical description suggested to those who had not already begun creating, that they work on less technical solutions.

All of the engineers' drawings and verbal comments were collected using an electronic pen that tracked its own movements and simultaneously recorded verbal data. This technique allowed us to recreate each participant's session for analysis.

\section{DataAnalysis}

Verbal data from the sessions were transcribed to supplement the sketching data. This collection of data was reviewed multiple times as we searched for evidence of how designers generated ideas and transitioned from one concept to another. Consistent with our previous work, in the retrospective interviews, most participants were not able to recall or describe their use of specific ideation strategies or product characteristics (Yilmaz \& Seifert, 2011). Consequently, most of our observations were drawn from our analysis of the concept sketches and think-aloud comments, rather than from the retrospective accounts of ideation approaches. 
The focus of the data analysis was the extraction of Design Heuristics. This method involves a close examination of each concept, its labels and description written by the engineer, and the analysis of the flow of concepts across the session. This extraction method was used successfully in prior studies to capture the relevant similarities among engineers' designs on a given task (Yilmaz \& Seifert, 2010, 2011). This study used the same method to note systematic strategies evident in the concepts on a novel design task, with data collected in a single design session from each participant.

We analyzed each participant's concepts (the sketch with accompanying think-aloud data and retrospective interview data) for evidence of idea generation strategies. Two coders, both trained designers with Ph.D. credentials, analyzed all of the data separately. Any disagreements in coding were resolved through discussion. The coders examined the data from each subject session separately, considering each concept separately and in sequence, for evidence of strategy use. Coding began with a master list of 74 Design Heuristics, and each concept was examined at length and coded for the presence of specific heuristics. The master list included all of the Design Heuristics identified in previous studies (Daly et al., 2010; Yilmaz \& Seifert, 2010, 2011).

In the analysis of each participant's concept set, we looked for characteristic differences between concepts; that is, the first concept was compared with all subsequent concepts, and then the second concept was compared with all subsequent concepts, and so on. We identified (1) characteristics that differentiated each participant's ideas from each other (i.e., how one concept compared to the others in a participant's set), (2) what transformations moved participants from one concept to the next (i.e., how characteristics of a set of concepts were similar and different, as well as how participants described the transformation), (3) participants' comments on the source of their ideas as they worked through the task, and (4) participants' explanations of how they proceeded through the design task in the retrospective interview. The goal was to find all strategies of any kind that were evident in the concepts generated by participants.

As an example of this analysis method applied to the solar cooker design task, consider Figure 1, which shows two concepts from Participant 36. The first concept used freestanding constructed legs for support, while the second used ropes tied to trees, suggesting the Design Heuristic called Incorporating the environment. The first concept used a reflective sheet, whereas the second used solar panels, showing a substitution of the functional method of capturing solar energy. Both concepts used components that could attach and detach, improving portability.

We also looked for evidence of heuristics within single concepts. Concept 5 from Participant 28, presented in Figure 2, provides an example of features detected within a single concept. The concept is a closed black box for holding food with an attached glass lens to focus sunlight. The outside of the box has mirrors to direct light to the lens, and the inside of the box has mirrors to direct the incoming light onto the food. The lens attachment is adjustable to capture the position of the sun.

One Design Heuristic observed here was Utilize opposite surface, where the inside surface of the box was used to support mirrors. Another Design Heuristic observed in this example was Use multiple components for one function, where the lens to focus light is combined with reflectors to maximize input. Add motion is also evident in how the lens and mirrors on top can rotate to face the sun. Repeat is evident in how the array of mirrors is repeated on both sides of the lens. Finally, Cover or wrap was evident because the designer chose to enclose the food within a black exterior shell. 


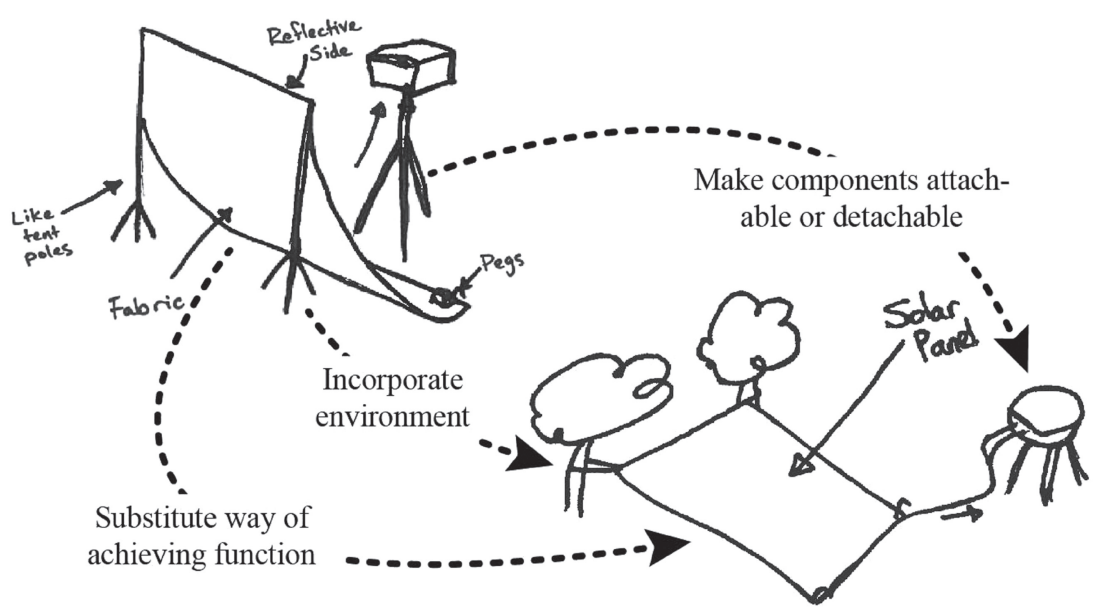

FIGURE 1. Examples of two concepts from one participant in sequence.

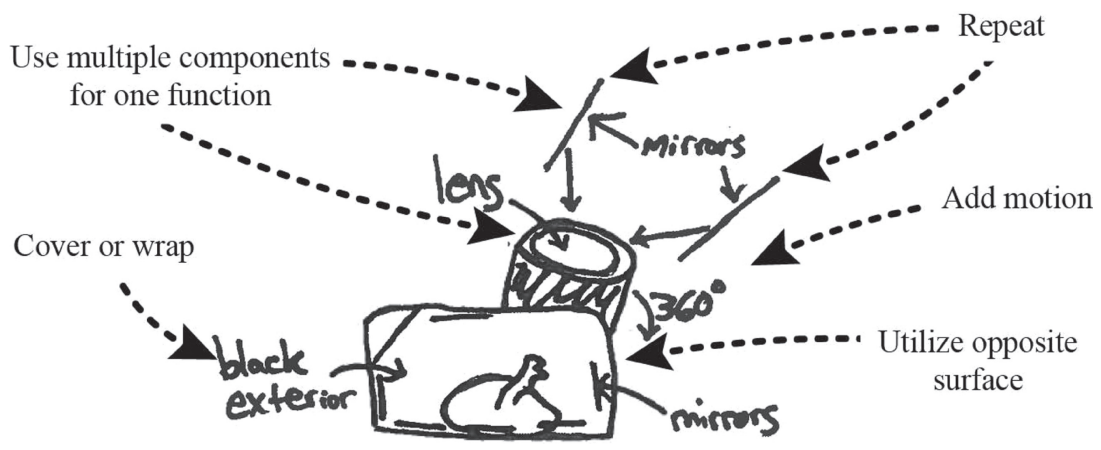

FIGURE 2. Example analysis of a single concept.

Each concept was coded for the identification of specific Design Heuristics. If a participant used the same heuristic in two different concepts, it was counted two times. However, if a Design Heuristic was evident only through a transition from one concept to another, it was counted only in the latter concept.

In addition to the Design Heuristic analysis, we also coded all other identified strategies we detected in the concepts. We began with the list in Table 1; however, we quickly found that few participants used these specific strategies in their entirety. Instead, we found that participants used smaller aspects of these methods or formed their own approaches. They did not explicitly refer to any of the existing methods and did not follow the proposed procedure of the method. One participant, for example, stated that he attempted to think about different varieties of food and then generated solar cooking methods adapted to each food (e.g., coffee or bread). The morphological 
analysis procedure (Allen, 1962; Zwicky, 1969) includes identifying each functional goal, considering the different ways of achieving each of those goals of the product, and combining them in different ways. Because this participant's approach to modify one functional dimension did not capture the multidimensional aspect of morphological analysis, it was coded as a separate strategy and added to the master list.

Finally, new strategies were observed that could not be identified as falling into a known Design Heuristic or any known approach from Table 1. Each observed strategy was added to the master coding list and counted with each occurrence. The result of this extraction analysis was an inclusive list of concept generation strategies observed anywhere in the protocol data.

\section{FINDINGS}

In total, the 36 engineers generated 179 concepts; the highest number of concepts generated by one participant was nine, and the fewest, one, with an average of five $(S D=2.2)$ per participant. We first present evidence of ideation strategies used by participants that emerged from our analysis. These included general methods for initiating concepts from a starting point, altering the problem description, and working from existing concepts. Next, we present evidence for the use of Design Heuristics with a complete list of heuristics evident in the data.

\section{Approaches to Idea Generation}

No participants stated that their approach to concept generation was based on existing ideation methods such as those shown in Table 1. In many cases, there were similarities between a component of the participant's approach and an aspect of an existing method. However, in no cases did the participants follow the prescribed procedure of the method, nor did they refer to the specific method during the think-aloud task or the retrospective interview. We considered these methods as general approaches to idea generation. In total, we identified 11 general approaches participants employed to help generate concepts, which we categorized into three groups: finding a starting point, reformulating the problem, and working from prior concepts.

Finding a starting point When given the problem statement and tasked to generate concepts, some participants used structured ways to create a basis for a design. We found evidence of four methods that participants used to find starting points during concept generation. These methods focus on the use of past exemplars, including analogies, other existing products, and past autobiographical experiences (see Table 3).

The use of both verbal and visual analogies by participants was closely related to the analogical thinking concept generation method. Analogical thinking involves two stages: (1) identification and retrieval and (2) mapping and transfer (Casakin, 2003; Finke et al., 1992; Holyoak \& Thagard, 1995; Perkins, 1997). Participants who used this technique considered features of their concepts that could be addressed through analogies with existing objects and transferred those to a solar oven design (Linsey et al., 2006). Participants also often referred to their previous experiences cooking food and cooking or heating using the sun as a way to initiate an idea. Additionally, participants found starting points by modifying existing cooking products. These approaches can be considered case-based reasoning, in which problem solvers adapt old solutions to meet new demands (Kolodner, 1993; 1997; Kolodner \& Wills, 1993). A final strategy involved designing from first 
TABLE 3

Methods Participants Used to Find a Starting Point

\begin{tabular}{ll}
\hline \multicolumn{1}{c}{ Strategy } & \multicolumn{1}{c}{ Description of evidence (The participant ...) } \\
\hline $\begin{array}{l}\text { Analogize } \\
\text { (Analogical thinking) }\end{array}$ & $\ldots$ used a form or functional analogy to initiate a design. \\
$\begin{array}{l}\text { Draw from previous experience } \\
\text { (Case-based reasoning) }\end{array}$ & $\ldots$ identified personal experiences that related to the task. \\
$\begin{array}{l}\text { Initiate ideas from simple forms } \\
\begin{array}{l}\text { Redesign existing product } \\
\text { (Case-based reasoning) }\end{array}\end{array}$ & $\begin{array}{l}\text { asound them. } \\
\text { aroustarted with an existing product and modified its features. }\end{array}$ \\
\hline
\end{tabular}
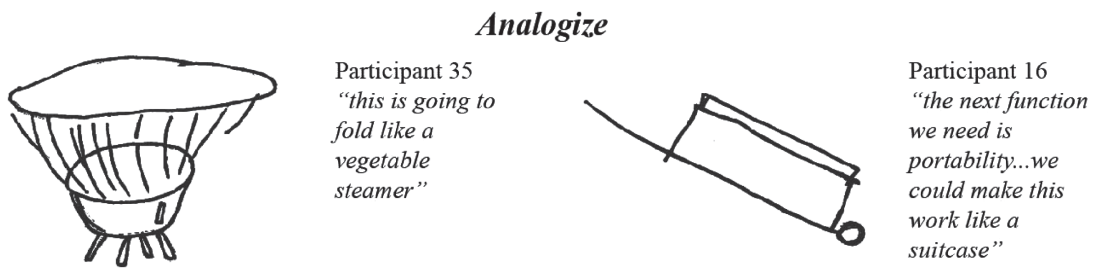

Figure 3. Analogize examples.

principles, where participants started with a simple form chosen apparently at random, and used it as the basis for a concept, then derived a solution following basic engineering principles (Cross \& Cross, 1998).

Two examples of the analogize method with excerpts from participant protocols are shown in Figure 3.

Reformulating the problem Some participants voiced their own values, interests, and concerns when interpreting the design task. They seemed to reshape the focus of the design problem by emphasizing specific priorities, evaluating aspects of the problem they wanted to improve, or modifying it to reflect what they considered to be the actual problem. Previous studies have demonstrated that problem reformulation (also called problem finding and problem framing) is an important step in the design process that is interleaved with idea generation (Csikszentmihalyi \& Getzels, 1971; Chand \& Runco, 1993; Volkema, 1983). While these problem reformulation strategies are not closely related to any existing idea generation strategies, all are components of design process models (Cross, 2000; Dubberly, 2004; Dym \& Little, 2009). Descriptions of the ways in which participants reformulated the problem are included in Table 4.

In this category of ideation methods, we often observed participants using evaluative criteria to guide concept generation by identifying flaws in concepts and then using those concerns to focus alternatives. Evidence for this approach was generally found in verbal data, where participants made value judgments about their concepts in the ideation session. Two examples are shown in Figure 4.

Participants also applied their own values to the constraints and requirements of the design task. When they identified a certain feature as essential, they focused on it to help 
TABLE 4

Ways Participants Reformulated the Design Problem

\begin{tabular}{ll}
\hline \multicolumn{1}{c}{ Strategy } & \multicolumn{1}{c}{ Description of evidence (The participant...) } \\
\hline Evaluate & $\begin{array}{l}\text {... identified a problem in individual elements of a concept and used this } \\
\text { judgment to generate alternatives. } \\
\text { Prioritize constraints }\end{array}$ \\
Restructure the problem & $\begin{array}{l}\text { guide concept development. } \\
\text {... redefined the "real" problem according to personal values, and used the } \\
\text { new definition to generate concepts. }\end{array}$ \\
\hline
\end{tabular}

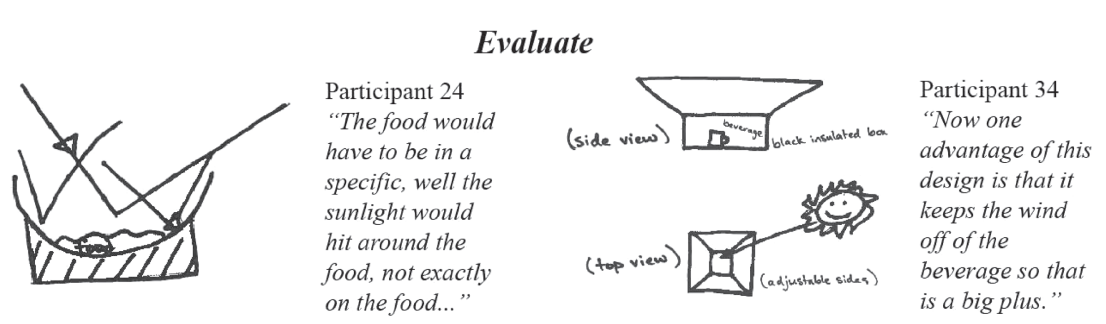

FIGURE 4. Evaluate examples.

generate a concept. For example, if they prioritized heat adjustability, they focused on this feature in their concept generation.

Less frequently, participants reconsidered the design problem and created an alternative version. For example, Participant 36 flexibly interpreted what it meant to cook in the problem statement, and designed a smoker concept: "And then I thought, well you might not just want to cook, you might want to dry foods. So, drying herbs and things like that you wouldn't need it to be nearly as hot ... I thought, okay, so instead of just drying food there's also the whole idea that you could slowly smoke food." Reformulating the problem served as a means to initiate new concepts.

Working from existing concepts Participants often used their existing concepts as a source for additional ones by modifying, merging, dividing, and building upon them, as described in Table 5.

Sometimes, participants used single concepts to build new ideas by adding detail and elaborating on features or clarifying aspects of the previous concept, a method similar to the elaboration step in SCAMPER. They also extracted aspects of a previous concept and built a new concept around it, analogous to the substitute step of SCAMPER. For example, Participant 28 identified a general form for the cooking chamber and then devoted his entire session to generating multiple attachments and variations of this same basic form. Participants also combined and merged aspects of multiple concepts to generate additional concepts, similar to SCAMPER's combine. Figure 5 provides one example of synthesizing concepts.

Finally, we observed participants emulating aspects of morphological analysis by identifying various ways to achieve each function of the solar cooker and thus quickly creating many concepts. Diversify ways of achieving function was most often observed as a way to work from previous concepts; participants generally had a concept and 
TABLE 5

Generation Methods Working from Existing Ideas

\begin{tabular}{ll}
\hline \multicolumn{1}{c}{ Strategy } & \multicolumn{1}{c}{ Description } \\
\hline $\begin{array}{l}\text { Split a concept } \\
\text { aspects of SCAMPER) }\end{array}$ & $\begin{array}{l}\text { Took the basic functioning structure of a previous concept or a } \\
\text { unique feature, and rebuilt a new concept around it } \\
\text { Elaborate } \\
\text { (aspects of SCAMPER) }\end{array}$ \\
$\begin{array}{l}\text { Synthesize } \\
\text { (aspects of SCAMPon a foundational concept by increasing the level of detail }\end{array}$ \\
$\begin{array}{l}\text { Diversify way of achieving } \\
\text { function (aspects of } \\
\text { morphological analysis) }\end{array}$ & $\begin{array}{l}\text { Took two or more previous concepts and merged them } \\
\text { new mechanism that could achieve the same function }\end{array}$ \\
\hline
\end{tabular}

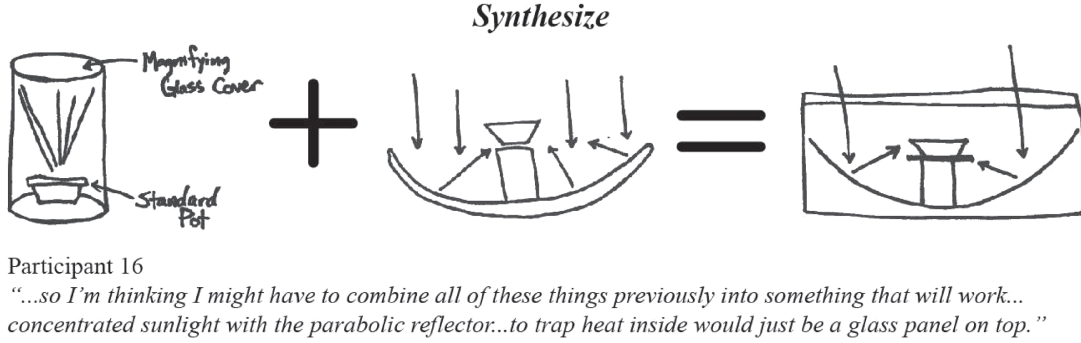

FiguRE 5. Synthesize examples.

identified one of its functions that could be achieved in another way. For example, Participant 28 designed a black box with a magnifying glass on top to collect the sunlight and then, instead of using the magnifying glass, he designed the same black box with a solar panel to collect the sunlight. However, participants occasionally used this method to find a starting point. For example, Participant 16 listed potential materials for the product at the beginning of his session before generating any concepts.

These three approaches for generating ideas - finding a starting point, reformulating the problem, and working from prior concepts - describe some of the ways participants created concepts. They also utilized another ways of generating ideas, what we call the Design Heuristics approach, where participants focused on the characteristics and features that products could have.

\section{Design Heuristics}

From the protocols collected for this study, we identified 62 Design Heuristics that participants applied to generate concepts. Fifty-three of these were identified in previous research (Daly et al., 2010; Yilmaz \& Seifert, 2010, 2011), and nine were new strategies that emerged in the analysis, and were identified as new Design Heuristics. Twenty-one that were uncovered in our previous work did not appear in this design problem. The heuristics evident in this study and descriptions of the associated evidence are presented in Table 6.

Figure 6 provides two instances of six Design Heuristics observed from participant concepts to illustrate how we identified them. An excerpt from the protocol is included to provide evidence of the heuristic use. 
The Design Heuristic Adjust function through movement describes concepts in which participants created moving parts that could adjust the core function of the product. The moving parts performed the same function, but moved to control the level of that function (e.g., how much sunlight is captured or how hot the oven gets). As shown in Figure 6, Participant 4 created a box with adjustable side reflecting panels to control heat, while Participant 27 created a tripod stand with a parabolic dish that can swivel to face the sun for the same function. Another Design Heuristic, Change flexibility, captured cases where participants substituted a flexible material for a rigid one, or vice versa. As shown in Figure 6, Participant 26 created a flexible, transparent food bag to replace a rigid pot, and Participant 36 used reflective blankets instead of rigid mirrors.

For Contextualize, evidence included concepts that made use of the locations where users would cook. These concepts included places such as campsites, community centers, and stores, and built upon an assumed context. As shown in Figure 6, Participant 31 designed a system for creating iced tea in a café setting, while Participant 36 created a largescale device for a park in which community members could place their food dishes to cook. For Create system, concepts were identified that included multistage processes moving through more than one functional component or multiple phases to complete the function. Often, participants created systems by heating an alternative fluid that would then be used to cook the food. Participant 24 heated water in a long black tube and then used it to heat the underside of a parabolic dish. After identifying heat loss as a problem with lidded pots, Participant 31 created a device in which food (beans) could be inserted in one end, cooked, and then automatically dispensed.

Impose bierarchy on functions was evident in concepts that included a set of tasks that need to be performed in a particular order to achieve the function. This is distinguished from Create system by the hierarchical structure of the components and the focus on controlling user interaction with the system. As shown in Figure 6, Participant 7 created a set of absorbent black cubes that must be put in the sun to collect heat before being placed in the grill to cook the food, and Participant 29 created a cooking device that requires the user to fold down the reflectors in order to access the food compartment. Figure 6 shows concepts with the Design Heuristic Repeat, where multiple similar elements allowed larger functions to be created out of smaller parts or increased the functional intensity of the product. Participant 17 replaced a single metal sheet with multiple mirror tiles make a parabolic dish, and Participant 9 used multiple mirrors to direct sunlight towards the food.

Each Design Heuristic in Table 6 was identified within the protocols between 1 and 100 times (average $=15$ ). The three most frequently observed Design Heuristics were Cover or wrap (100 occurrences), Attach independent functional components (95 occurrences), and Repeat (69 occurrences). We hypothesize that the nature of the design problem influences which Design Heuristics show up most frequently. For example, participants identified retaining heat as essential to cooking with solar energy, and therefore they often covered or enclosed a cooking chamber. Since the design problem calls for a compact and portable product, many components (such as reflectors, mirrors, and cooking surfaces) were often attached. Lastly, since the participants were generally aware that natural sunlight is not intense enough to cook food, they often repeated elements to collect more light and intensify it on the food. Some of the Design Heuristics observed in our previous studies were used less frequently by participants in 
TABLE 6

Design Heuristics Extracted from Participant Concepts

\begin{tabular}{|c|c|}
\hline Heuristic & Description of evidence \\
\hline Add features from nature & The product has features that mimic nature \\
\hline Add motion & The product or a component can move by itself \\
\hline Add to existing product & The product attaches to or functions with a product that already exists \\
\hline $\begin{array}{l}\text { Adjust function through } \\
\text { movement }\end{array}$ & $\begin{array}{l}\text { The level of the product's function can be adjusted by the user by moving } \\
\text { components }\end{array}$ \\
\hline $\begin{array}{l}\text { Adjust functions for } \\
\text { specific users }\end{array}$ & The product is designed for specific users with different needs \\
\hline $\begin{array}{l}\text { Apply existing mechanism } \\
\text { in new way }\end{array}$ & $\begin{array}{l}\text { The product incorporates a repurposed existing product as a functional } \\
\text { component }\end{array}$ \\
\hline $\begin{array}{l}\text { Attach independent } \\
\text { functional components }\end{array}$ & $\begin{array}{l}\text { The product has physical connections between multiple components that } \\
\text { each serve distinct, separate functions }\end{array}$ \\
\hline Attach product to user & The product can be attached to the user \\
\hline Bend & $\begin{array}{l}\text { The product or its components have bends in surfaces that were assumed } \\
\text { or previously existed as flat }\end{array}$ \\
\hline Build user community & $\begin{array}{l}\text { The product is designed to support use by various people or to unite a } \\
\text { community toward a common goal }\end{array}$ \\
\hline Change contact surface & $\begin{array}{l}\text { The points of contact where users are intended to interact with the } \\
\text { product are visually or tactilely distinguished }\end{array}$ \\
\hline Change flexibility & A component with an assumed flexibility is made more or less flexible \\
\hline Change geometry & $\begin{array}{l}\text { A component with an assumed or previously existing geometry is } \\
\text { recreated with a new geometric form }\end{array}$ \\
\hline Compartmentalize & $\begin{array}{l}\text { The product has multiple compartments to store different components } \\
\text { or items or to serve different functions }\end{array}$ \\
\hline Contextualize & The product is designed to fit within a specific context \\
\hline Convert 2-D to 3-D & $\begin{array}{l}\text { The three-dimensional product or a component is made from a two- } \\
\text { dimensional sheet material }\end{array}$ \\
\hline $\begin{array}{l}\text { Convert for second } \\
\text { function }\end{array}$ & The product can be converted to serve a secondary function \\
\hline Cover or wrap & $\begin{array}{l}\text { A volume, a component, or the entire product is wrapped or covered with } \\
\text { material for protection or containment }\end{array}$ \\
\hline Create system & $\begin{array}{l}\text { The product incorporates a multistage process in which a medium moves } \\
\text { through more than one functional component, or goes through multiple } \\
\text { phases to complete the function. }\end{array}$ \\
\hline $\begin{array}{l}\text { Distinguish functions } \\
\text { visually }\end{array}$ & The different functions of the product are visually distinguished \\
\hline Divide continuous surface & $\begin{array}{l}\text { A surface of the product is physically separated or visually divided into } \\
\text { multiple surfaces that each serve different functions }\end{array}$ \\
\hline Elevate or lower & $\begin{array}{l}\text { The product is lifted off the ground with a stand or through attachment } \\
\text { to its environment }\end{array}$ \\
\hline Expand or collapse & The product is expandable and collapsible to change size for use \\
\hline Extend surface & $\begin{array}{l}\text { The surfaces of the product are longer or wider than the assumed or } \\
\text { previous size }\end{array}$ \\
\hline Extrude & The product came from an extrusion of a flat shape \\
\hline
\end{tabular}


TABLE 6 Continued

\begin{tabular}{|c|c|}
\hline Heuristic & Description of evidence \\
\hline Flatten & $\begin{array}{l}\text { The product can be flattened from a non-flat shape, or the product is flat } \\
\text { in comparison to its assumed or previously existing shape }\end{array}$ \\
\hline Fold & $\begin{array}{l}\text { Joints or flexibility in the product allow it to be folded down to a smaller } \\
\text { size }\end{array}$ \\
\hline Hollow out & A volume of the product is hollow \\
\hline $\begin{array}{l}\text { Impose hierarchy on } \\
\text { functions }\end{array}$ & $\begin{array}{l}\text { The function of the product can only be achieved when the user follows a } \\
\text { series of steps }\end{array}$ \\
\hline Incorporate environment & $\begin{array}{l}\text { The product is physically incorporated into its environment, such that } \\
\text { the environment plays a role in the function of the product }\end{array}$ \\
\hline Incorporate user input & $\begin{array}{l}\text { The product has an interface that allows the user to input preferences to } \\
\text { modify its function }\end{array}$ \\
\hline $\begin{array}{l}\text { Make component } \\
\text { multi-functional }\end{array}$ & A component serves multiple functions \\
\hline $\begin{array}{l}\text { Make components } \\
\text { attachable or detachable }\end{array}$ & $\begin{array}{l}\text { Individual, separate components of the product have connectors that } \\
\text { allow them to be attached or detached }\end{array}$ \\
\hline $\begin{array}{l}\text { Merge functions with } \\
\text { same energy source }\end{array}$ & $\begin{array}{l}\text { The product incorporates two or more functions that use the same } \\
\text { energy source }\end{array}$ \\
\hline Merge surfaces & $\begin{array}{l}\text { The product has a single continuous surface where two or more surfaces } \\
\text { were assumed or previously existed }\end{array}$ \\
\hline Mirror or array & $\begin{array}{l}\text { The components of the product are mirrored or arrayed along a central } \\
\text { axis or in a pattern }\end{array}$ \\
\hline Nest & The components of the product are shaped to fit inside each other \\
\hline Offer optional components & $\begin{array}{l}\text { The product has multiple optional components among which the user } \\
\text { can decide }\end{array}$ \\
\hline Provide sensory feedback & $\begin{array}{l}\text { The product can return sensory information to the user that describes the } \\
\text { function or status of the product }\end{array}$ \\
\hline Reconfigure & $\begin{array}{l}\text { The components of the product can be reconfigured, or they have been } \\
\text { reconfigured from an existing or assumed state }\end{array}$ \\
\hline Reduce material & The product uses less material than the assumed amount \\
\hline Reorient & $\begin{array}{l}\text { The product can be flipped vertically or horizontally to serve a different } \\
\text { function }\end{array}$ \\
\hline Repeat & Multiples of the same functional component \\
\hline $\begin{array}{l}\text { Reverse direction or } \\
\text { change angle }\end{array}$ & $\begin{array}{l}\text { The product is directed or angled differently than the assumed or previ- } \\
\text { ously existing direction or angle }\end{array}$ \\
\hline Roll & The product can be rolled along an axis \\
\hline Rotate & The product or a component can rotate about an axis \\
\hline Scale up or down & The product is larger or smaller than its existing or assumed size \\
\hline Separate parts & $\begin{array}{l}\text { Different functioning components of the product are physically separat- } \\
\text { ed into distinct parts }\end{array}$ \\
\hline Slide components & The components of the product can slide along each other \\
\hline Stack & $\begin{array}{l}\text { The components of the product are vertically oriented to rest on each } \\
\text { other }\end{array}$ \\
\hline
\end{tabular}


TABLE 6 Continued

\begin{tabular}{|c|c|}
\hline Heuristic & Description of evidence \\
\hline $\begin{array}{l}\text { Substitute way of } \\
\text { achieving function }\end{array}$ & $\begin{array}{l}\text { An assumed or previously existing component is replaced with a new one } \\
\text { that will serve the same function }\end{array}$ \\
\hline Synthesize functions & $\begin{array}{l}\text { The product incorporates multiple functions that work together to } \\
\text { achieve its final goal }\end{array}$ \\
\hline Telescope & The product or a component can be made smaller or larger by telescoping \\
\hline Texturize & The product has one or more surface with a distinct texture \\
\hline Unify & $\begin{array}{l}\text { The components share common geometries and form similarities that } \\
\text { unite into a cohesive product }\end{array}$ \\
\hline $\begin{array}{l}\text { Use alternative energy } \\
\text { source }\end{array}$ & $\begin{array}{l}\text { The product uses a different energy source than the assumed to achieve } \\
\text { its function }\end{array}$ \\
\hline $\begin{array}{l}\text { Use common base to } \\
\text { hold components }\end{array}$ & The product has a central base that holds multiple components \\
\hline $\begin{array}{l}\text { Use multiple components } \\
\text { for one function }\end{array}$ & $\begin{array}{l}\text { Multiple components work together to achieve the core function } \\
\text { of the product }\end{array}$ \\
\hline $\begin{array}{l}\text { Use packaging as } \\
\text { functional component }\end{array}$ & $\begin{array}{l}\text { The packaging of the product can be used to help achieve the core } \\
\text { function }\end{array}$ \\
\hline $\begin{array}{l}\text { Use recycled or recyclable } \\
\text { materials }\end{array}$ & Recycled or recyclable materials are incorporated into the product \\
\hline Utilize inner space & $\begin{array}{l}\text { The inner space of the product or a component is used for a distinct } \\
\text { function }\end{array}$ \\
\hline Utilize opposite surface & $\begin{array}{l}\text { Both sides of a surface, such as top and bottom, front and back, or inside } \\
\text { and outside, are used }\end{array}$ \\
\hline
\end{tabular}

this study, suggesting that the use of heuristics may depend upon features of the problem. For example, the heuristic Use human generated power was not observed at all in this study because of the nature of the design task.

While the focus of our analysis was qualitative, we conducted some descriptive analyses to provide comparative information on heuristic use. In particular, we collected protocols from individuals with expertise ranging from college training through professional experience and investigated relationships between experience and the use of heuristics. The highest number of Design Heuristics evident in any participant's set of concepts was 26 , and the lowest 6 , with an average of 14 . Twenty-three participants had four or fewer years of experience (were undergraduate students), and the remaining 13 participants had more than 4 years of experience (graduate students, instructors, and professionals). The more-experienced participants used more (different) heuristics on average (17), while less-experienced participants averaged only 12, $t(19.362)=2.836, p<0.012$ (two tailed Welch $t$-test). That more-experienced participants used more heuristics is in line with Anderson's (1982) definition of expertise: the skilled execution of highly practiced sequences of procedures. These results also support prior suggestions that heuristic use may follow a developmental sequence, from learning individual heuristics and becoming skilled in their application, to eventually developing patterns of multiple heuristic applications (Yilmaz \& Seifert, 2011).

While there was abundant evidence of the use of Design Heuristics, participants often did not refer to their use in the protocols. Participants did not suggest in the retrospective 


\section{Adjust function through movement}

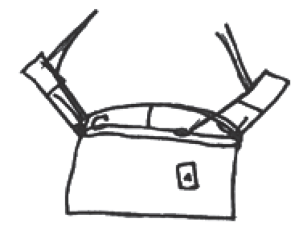

Participant 4

"Mirrors can fold

down so that it's portable"

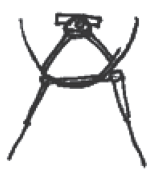

Participant 27

"....orient it, so

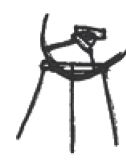

here we should

have here an

adjustable

surface...this would be able to pivot."

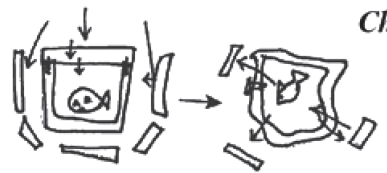

Change flexibility

Participant 26

"there's nothing here that says it needs to be a pot...it might be more effective to just have a bag."

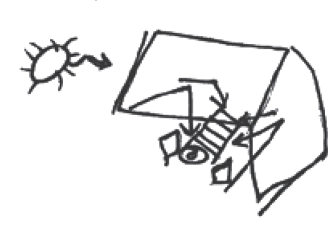

Participant 36

"Let's see...other" types of structural support... There's these blankets that are reflective."

\section{Contextualize}

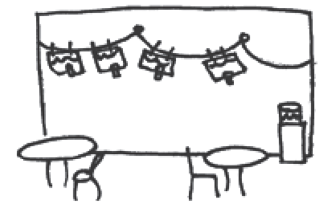

Participant 31

"Make iced tea in zip locks.

Eco-concious cafe."

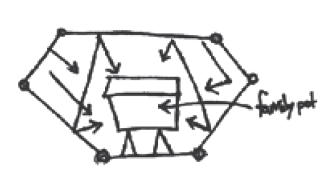

Participant 36

"The inner piece could be...provided by the community,

the person, the family."

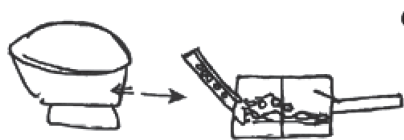

Participant 31

" $a$ way that you could (check if it was done) without opening the system...save heat...some sort of process

Create system

where as you go across it's more and more done"

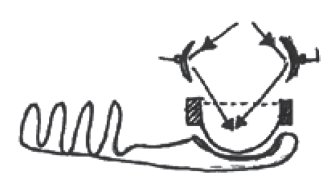

Participant 24

"We have a water system... which is linked to the food... So there is a water circuit"

\section{Impose hierarchy on functions}

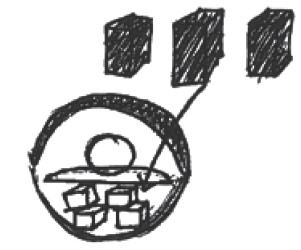

Participant 7 "you could heat tip... bricks...in the same dust bowl that they use to cook...and the food plate could be moved on top of it."
Participant 29 "just pull it up, and it deploys... person's getting their food...make more sense if they undeployed the mirrors and opened it"

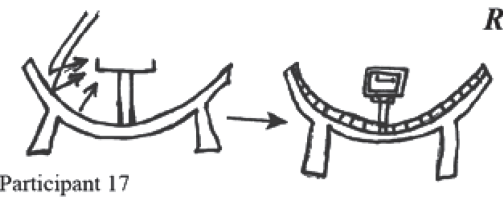

"rather than have an entire sheet... have little mirror tiles... potentially taken from larger mirror segments."

Repeat

FIGURE 6. Examples of observed design heuristics.

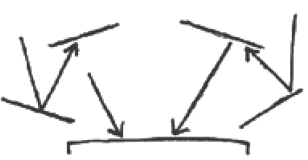

Participant 9

"I think we need maybe four mirrors...sunlight goes to here, then to here, then to here." 
interview that the application of different heuristics was their strategy for idea generation, nor did they indicate as they were designing that their intentions were to change characteristics of the product. Participants verbalized individual decisions about concepts by saying, "What if I folded this?" or "If I covered this piece, ... "These ideas did not, however, translate to applying diverse ideation strategies. Thus, participants made choices in terms of how to initiate and modify concepts but did not or could not verbalize these strategies in generating ideas. Rather, Design Heuristics were applied and discussed as a form of implicit knowledge, as is often seen in heuristic use in experts (Klein, 1998; Nisbett \& Ross, 1980).

However, both in the retrospective interviews and during the task, participants verbalized more general strategies, such as using analogies, putting together combinations of concepts, considering related products, drawing on experiences related to the task, and allowing ideas to appear in their heads. The ability to verbalize specific strategies was especially true for those with more experience. For example, when reflecting on the task, Participant 36 described how he Synthesized two concepts to create a third. He also recognized and identified the constraints that drove his design ideas and the ways he modified the problem statement.

In addition to the nature of the task, participants' priorities also seemed to determine the application of heuristics. Participants often verbalized their goals for their concepts, emphasizing certain constraints and requirements over others, including portability, cost, and user interactions. These goals seemed to reframe the ways participants viewed the design problem, which also influenced the heuristics they applied to their exploration of the design space. There may be systematic relationships between specific Design Heuristics and the problem criteria that give rise to their use. Future studies comparing heuristic use across varied problem content may reveal systematic factors in their use.

\section{Discussion}

\section{Ideation Strategies}

This study focused on extracting the methods used in idea generation by engineers as they designed a novel device. The results revealed some general methods for initiating concepts, including using analogies and adding variations to prior concepts. We observed similarities among participants in the ways they worked through idea generation: how they found starting points, reformulated the problem, and worked from existing concepts. These general strategies are similar to proposed methods for concept generation as well as aspects of design process models.

Most significantly, the analysis found empirical support for the ubiquitous use of Design Heuristics in concept generation. This use of heuristics was observed in the concepts generated by participants across levels of experience - though we found that more experienced participants used more heuristics. This approach is also unique in that the specific guidelines have arisen through empirical testing with engineering designers. The Design Heuristics approach is a descriptive model, rooted in observations of engineers in action as they generated concept solutions. This development model for an idea generation technique allows us to capture unique information about strategy use that has not been captured in previous prescriptive approaches to idea generation. The extraction of heuristics from designers as they are designing results in empirically based guidelines, which we could not gain from designers' reports alone. 
Our past collection of studies to extract Design Heuristics allowed us to build this list of strategies. This study with engineering students and practitioners confirmed many of the heuristics we have seen across other problem contexts and also allowed us to extract additional heuristics. That we did not add a large number of heuristics indicates to us that we are close to a saturation point in our collection of strategies.

Design Heuristics share similarities to other ideation techniques, including SCAMPER. Like those approaches, Design Heuristics also serve as prompts to aid designers by suggesting directions for modifying existing concepts. However, while SCAMPER offers information about how to transform ideas, it may be difficult from its set of general guidelines (e.g., combine) to understand what to combine and how to apply the guidelines to the tasks. The TRIZ approach provides yet more specific design guidelines, but these address refinements in mechanisms and design trade-offs requiring concrete concept details. As a result, TRIZ strategies may be most suited to use in later stages of design, after concepts have been selected and further developed to the implementation stage. The synectics framework (Gordon, 1961) focuses on the fusion of opposites using past experiences and analogies; as a result, it is difficult to observe systematicities across designers since they have unique sets of experiences to draw upon. $\mathrm{IDEO}^{\mathrm{TM}}$ method cards emphasize ways to understand the end user rather than proposing specific design strategies, and Whack Pack cards (von Oech, 2010) focus on breaking out of habitual views by providing general techniques (take a different perspective on the problem) and decision-making advice (make a list of the pros and cons of each option). Most importantly, these methods are not supported by empirical evidence from engineers as they design.

\section{Design Heuristics in Engineering Education}

We envision a teachable approach to concept generation using the Design Heuristics, which would include representing each Design Heuristic on a separate card, and providing the set of cards to engineering students and practitioners as prompts for concept generation. As an example, we created the Design Heuristic card shown in Figure 7.

The Design Heuristic card represents one of the extracted strategies from our work; it includes a description of the heuristic, an abstract image depicting the application of the

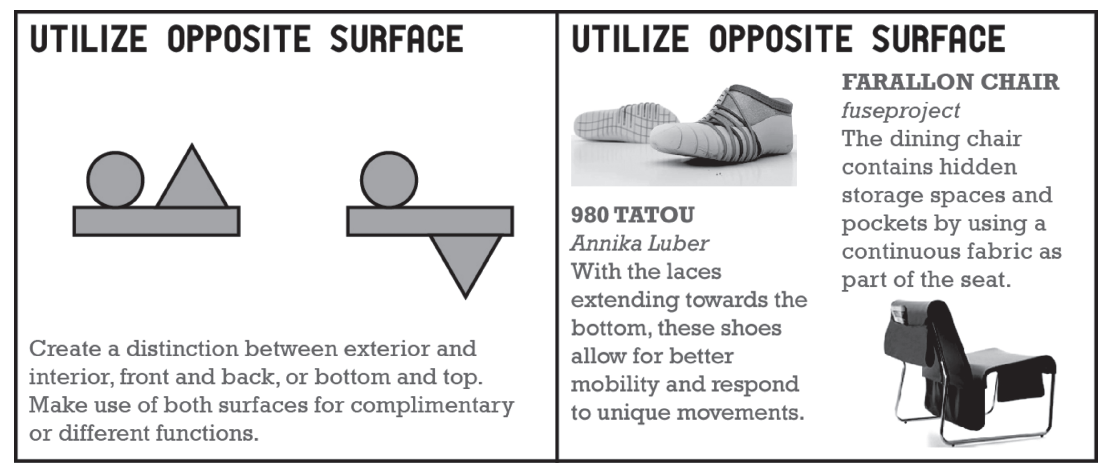

FigurE 7. Example Design Heuristic card (Images from: www.idsa.org/content/content1/980-tatousport-shoe-le-parkour, http://www.fuseproject.com/category-3-product-19). 
heuristic, and two product examples that show how the heuristic is evident in existing consumer products.

We anticipate that the Design Heuristics could be taught to engineering students in design courses, from freshman to capstone project-based courses, by instructing them how to use the cards with their course projects when they are trying to generate ideas. Instruction could be done in a relatively short amount of time because the cards would include multiple pieces of information about the strategy. The instruction would include an introduction to the Design Heuristics, how they were developed, an example card, and practice using a few cards with guidance by the instructor on a given design task. The students could then work with the full set or a subset of the cards to generate ideas. An introduction to the Design Heuristics cards and guidelines for their use could be included in a workshop or short instruction book for engineering practitioners.

Given the set of cards, engineering students and practitioners would have the collection of strategies at their disposal to aid their idea generation sessions. The collection of Design Heuristics could become part of the repertoire they apply when generating multiple and diverse design solutions. They may prompt engineering students and practitioners to modify concepts in ways they would not normally consider and expand the types of modifications applied, helping engineers more fully explore design spaces and leading to more creative and diverse sets of ideas.

\section{LIMITATIONS AND FUTURE WORK}

This study included only one design task, which may have limited the heuristics that were identified. However, our prior studies have also verified the extraction of Design Heuristics from a variety of design problems (Yilmaz \& Seifert, 2010, 2011; Yilmaz et al., 2012); thus the combined results of this and prior studies provide more credibility that these heuristics can be applied more broadly. An additional limitation was our use of a laboratory setting, with an artificial task and time frame, in contrast to participants' usual design environments and the flexibility of returning to ideation after doing other tasks, such as problem refinement, data gathering, and prototyping. However, the verification of the presence of Design Heuristics in this laboratory task suggests their potential relevance to the range of design problems and to design pedagogy for engineering education.

We have not yet developed a framework to subdivide the Design Heuristics because additional data is needed to determine what kinds of categorization, framework, and architecture would be valuable. We chose not to artificially group the Design Heuristics together; instead, that decision will be based on empirical evidence. Thus, in our future work, we will investigate patterns in heuristic use: whether certain heuristics are often used together or separately, and what types of criteria certain heuristics address in various problem contexts. These studies will guide if and what type of overarching framework would prove useful to engineering students and practitioners.

The long-term goal is to develop a collection of strategies that have been shown across a variety of design contexts to support diverse thinking in concept generation. Our goal is not to map all of the Design Heuristics possible but to develop a set of strategies that are useful in multiple problem contexts for the design of products. Thus, as we continue to study heuristic use in additional problem contexts, the list of Design Heuristics will be further refined, based on observations about their use. Future studies are necessary to examine how the nature of the design problem affects the use of Design 
Heuristics and whether systematic patterns of use occur. Another avenue of research is to examine the impact of professional training on heuristic use, following up on the finding that experts appeared to use more heuristics in their concepts. Finally, a larger question is whether these or other heuristics appear in other parts of the design process.

\section{CONCLUSIONS}

Engineering students and practitioners develop design skills and approaches to ideation through their practice of design. However, it is difficult for designers to recognize their cognitive strategies, making it a challenge to share these ideation methods with others. This study of engineering designers provides a collection of heuristics observed in practice that offers new methods for students and practitioners to explore design spaces. The Design Heuristics identified in this and previous work can potentially be learned and then incorporated into the practice of engineering students and practitioners.

The Design Heuristics are not rules for design that must be followed. Neither do they work alone to generate ideas that are not due to the designer. Rather, they serve as strategies to facilitate one's own ideation process, building upon ideas while increasing the variety of ways they are expressed. It appears a natural consequence of idea generation to become fixated on a current idea. By their nature, Design Heuristics help an individual build upon that idea to create endless variations, combining and developing ideas in unusual directions. As a result, engineers using Design Heuristics may have an easier time generating more, and more different, concepts within a work session. If Design Heuristics prove helpful in supporting engineers to generate novel and creative designs, innovative solutions will follow.

\section{ACKNOWLEDGEMENTS}

This material is based upon work supported by the National Science Foundation under Grant No. 0927474. Any opinions, findings, and conclusions or recommendations expressed in this material are those of the authors and do not necessarily reflect the views of the National Science Foundation.

We would also like to thank Panos Y. Papalambros for his contributions to our research agenda.

\section{REFERENCES}

ABET Board of Directors. (2011). 2011-2012 Criteria for accrediting engineering programs. Retrieved August 30, 2011, from http://www.abet.org/forms.shtml.

Ahmed, S., Wallace, K. M., \& Blessing, L. T.M. (2003). Understanding the differences between how novice and experienced designers approach design tasks. Journal of Research in Engineering Design, 14(1), 1-11.

Akin, O. (1990). Necessary conditions for design expertise and creativity. Design Studies, 11(2), 107-113.

Akin, O., \& Lin, C. (1995). Design protocol data and novel design decisions. Design Studies, 16(2), 211-236.

Allen, M. (1962). Morphological creativity. New Jersey: Prentice-Hall.

Altshuller, G. (1984). Creativity as an exact science. New York: Gordon and Breach. 
Amabile, T. M. (1996). Creativity in context: Update to the social psychology of creativity. Boulder, CO: Westview Press.

Anderson, J. R. (1982). Acquisition of cognitive skill. Psychological Review, 89(4), 369-406.

Atman, C. J., Adams, R. S., Mosborg, S., Cardella, M. E., Turns, J., \& Saleem, J. (2007). Engineering design processes: A comparison of students and expert practitioners. Journal of Engineering Education, 96(4), 359-379.

Atman, C. J., \& Bursic, K. M. (1998). Verbal protocol analysis as a method to document engineering student design processes. Journal of Engineering Education, 87(2), 121-132.

Atman, C., Chimka, J., Bursic, K., Nachtmann, H. (1999). A comparison of freshman and senior engineering design processes. Design Studies, 20(2), 131-152.

Ball, L., Evans, J., \& Dennis, I. (1994). Cognitive processes in engineering design: A longitudinal study. Ergonomics, 37(11), 1753-1786.

Brophy, D.R. (2001). Comparing the attributes, activities, and performance of divergent, convergent, and combination thinkers, Creativity Research Journal, 13, 439-455.

Casakin, H. (2003). Visual analogy as a cognitive strategy in the design process: Expert versus novice performance. In N. Cross \& E. Edmonds (Eds.), Expertise in design. Sydney: University of Technology, Creativity \& Cognition Press.

Casakin, H., \& Goldschmidt, G. (1999) Expertise and the use of analogy: Implications for design education. Design Studies, 20(2), 153-175.

Chand, I., \& Runco, M. A. (1993). Problem finding skills as components in the creative process. Personality and Individual Differences, 14(1), 155-162.

Christensen, B., \& Schunn, C. (2009). "Putting blinkers on a blind man": Providing cognitive support for creative processes with environmental cues. In Wood, K., \&Markman, A. (Eds.), Tools for Innovation (pp. 48-74). Oxford University Press.

Christensen, B., \& Schunn, C. (2007). The relationship of analogical distance to analogical function and preinventive structure: The case of engineering design. Memory and Cognition, 35(1), 29-38.

Collins, B., \& Guetzkow, H. (1964). A social psychology of group problem solving. New York: John Wiley and Sons, Inc.

Cropley, D. H. (2006). The role of creativity as a driver of innovation. Proceedings of the 2006 IEEE International Conference on the Management of Innovation and Technology, Singapore.

Cross, N. (2000). Engineering design methods. West Sussex, England: John Wiley \& Sons.

Cross, N. (2001). Design cognition: Results from protocol and other empirical studies of design activity. In C. M. Eastman, W. M. McCracken, \& W. C. Newstetter (Eds.), Design knowing and learning: Cognition in design education (pp. 79-104). Amsterdam: Elsevier.

Cross, N., \& Cross, A. C. (1998). Expertise in engineering design. Research in Engineering Design, 10(3), 141-149.

Csikszentmihalyi, M., \& Getzels, J.W. (1971). Discovery-oriented behaviour and the originality of artistic products: A study with artists. Journal of Personality and Social Psychology, 19(1), $47-52$.

Dahl, D., \& Moreau, P. (2002). The influence and value of analogical thinking during new product ideation. Journal of Marketing Research, 39(1), 47-60.

Daly, S., Christian, J., Yilmaz, S., Seifert, C. M., \& Gonzalez, R. (2012). Assessing design heuristics in idea generation within an introductory engineering design course. International Journal of Engineering Education, 28(2), 1-11. 
Daly, S. R., Yilmaz, S., Seifert, C. M., \& Gonzalez, R. (2010). Cognitive heuristic use in engineering design ideation. Proceedings of the 2010 American Society for Engineering Education Conference (ASEE), Louisville, Kentucky.

de Bono, E. (1975). The uses of lateral thinking. New York: Harper and Row.

de Bono, E. (1992). Serious creativity: Using the power of lateral thinking to create new ideas. Toronto: HarperCollins Publishers Ltd.

Diehl, M., and Stroebe, W. (1987). Productivity loss in brainstorming groups: Toward the solution of a riddle. Journal of Personality and Social Psychology, 53(3) 497-509.

Dubberly, H. (2004). How do you design? Dubberly Design Office. Retrieved August 30, 2011, from http://www.dubberly.com/articles/how-do-you-design.html.

Duderstadt, J. (2008). Engineering for a changing world: A roadmap to the future of engineering practice, research, and education. Ann Arbor, MI: The Millennium Project. Retrieved August 30, 2011, from http://milproj.dc.umich.edu/.

Dym, C., Agogino, A., Eris, O., Frey, D., \& Leifer, L. (2005). Engineering design thinking, teaching, and learning. Journal of Engineering Education, 94(1), 103-120.

Dym, C., \& Little, P. (2009). Engineering design. Hoboken, NJ: John Wiley \& Sons.

Eberle, B. (1996). Scamper: Games and activities for imagination development. Waco, Texas: Prufrock.

Eckersley, M. (1988). The form of design processes: a protocol analysis study. Design Studies, 9(2), 86-94.

Ericsson, K., \& Simon, H. (1980). Verbal reports as data. Psychological Review, 87(3), 215-251.

Ericsson, K., \& Simon, H. (1993). Protocol analysis: Verbal reports as data (2nd ed.). Boston: The MIT Press.

Eris, O. (2004). Effective inquiry for innovative engineering design. Boston: Kluwer Academic Publishers.

Finke, R. A., Ward, T. B., \& Smith, S.M. (1992). Creative cognition: Theory, research, and applications. Cambridge, MA:The MIT Press.

Firestien, R. L. (1996). Leading on the creative edge: Gaining competitive advantage through the power of creative problem solving. Colorado Springs, CO: Piñon Press.

Gero, J. S., \& McNeill, T. (1998). An approach to the analysis of design protocols. Design Studies, 19(1), 21-61.

Gordon, W.J. J. (1961). Synectics. New York: Harper \& Row.

Grasso, D., Burkins, M. B., Helble, J., \& Martinelli, D. (2008). Dispelling the myths of holistic engineering. PE Magazine, 27-28.

Hannu, K., \& Pallab, P. (2000). A comparison of concurrent and retrospective verbal protocol analysis. American Journal of Psychology, 113(3), 387-404.

Harvard Business School Press (2003). Harvard business essentials: Managing creativity and innovation. Boston, $\mathrm{MA}$.

Holyoak, K.J., \& Thagard, P. (1995). Mental leaps: Analogy in creative thought. Cambridge, MA: The MIT Press.

Horowitz, R. (1999). Creative problem solving in engineering design. (Doctoral dissertation). TelAviv University.

IDEO. (2002). IDEO method cards. San Francisco, CA: William Stout Architectural Books. Retrieved August 30, 2011, from http://www.ideo.com/work/method-cards/.

Jansson, D. G., \& Smith, S. M. (1991). Design fixation. Design Studies, 12(1), 3-11.

Jin, Y., \& Benami, O. (2010). Creative patterns and stimulation in conceptual design. AI EDAM 24(2), 191-209. 
Klein, G. (1998). Sources of power: How people make decisions. Cambridge, MA: The MIT Press.

Klukken, P. G., Parsons, J. R., \& Columbus, P.J. (1997). The creative experience in engineering practice: Implications for engineering education. Journal of Engineering Education, 86(2), 133-138.

Kolodner, J., \& Wills, L. (1993). Case based creative design. Symposium on AI and Creativity. Stanford, CA.

Kolodner,J. (1993). Case-based reasoning. San Mateo, CA: Morgan-Kaufman.

Kolodner, J. (1997). Educational implications of analogy: A view from case-based reasoning. American Psychologist, 52(1), 57-66.

Laughlin, P. (2002). Groups perform better than the best individuals on letters-to-numbers problems. Organizational Behavior and Human Decision Processes, 88(2), 605-620.

Lewis, A.C., Sadosky, T.L., \& Connolly, T. (1975). Effectiveness of group brainstorming in engineering problem solving. IEEE Transactions of Engineering Management, 22(3), 119-124.

Linsey, J.S., Clauss, E.F., Kurtoglu, T., Murphy, J.T., Wood, K.L., and Markman, A.B. (2011). An experimental study of group idea generation techniques: Understanding the roles of idea representation and viewing methods. Journal of Mechanical Design, 133(3), 031008031023.

Linsey, J. S., Murphy, J. T., \& Markman, A. B. (2006). Representing analogies: Increasing the probability of innovation. Proceedings of IDETC/CIE 2006 ASME 2006 International Design Engineering Technical Conferences E Computers and Information in Engineering Conference, September 10-13, 2006, Philadelphia, Pennsylvania.

Linsey, J. S., Tseng, I., Fu, L. Cagan, J., Wood, K. L., \& Schunn, C. (2010). A study of design fixation, its mitigation and perception in engineering design faculty. Journal of Mechanical Design, 132,1-12.

Liu, Y. \& Bligh, T. (2003). Towards an 'ideal' approach for concept generation, Design Studies, 24(4), 341-355.

MacCrimmon, K., \& Wagner, C. (1994). Stimulating ideas through creativity software. Management Science, 40, 1514-1532.

Morgan, M. (1993). Creating workforce innovation: Turning individual creativity into organizational innovation. Sydney, Australia: Business and Professional Publishing.

Mullen, B., Johnson, C., \& Salas, E. (1991). Productivity loss in brainstorming groups: A metaanalytic integration. Basic and Applied Social Psychology, 12(1), 3-23.

National Academy of Engineering (n.d.). Grand challenges for engineering. Retrieved on August 30, 2011, from www.engineeringchallenges.org/

Newell, A. \& Simon, H. (1972). Human problem solving. Englewood Cliffs, NJ: Prentice-Hall.

Niku, S.B. (2009). Creative design of products and systems. NJ: John Wiley \& Sons, Inc.

Nisbett, R., \& Ross, L. (1980). Human inference: Strategies, and shortcomings of social judgment. Englewood Cliffs, NJ: Prentice-Hall.

Osborn, Alex (1953). Applied imagination: Principles and procedures of creative problem solving. New York, NY: Charles Scribner's Sons.

Pappas, J., \& Pappas, E. (2003). Creative thinking, creative problem-solving, and inventive design in the engineering curriculum: A review. Proceedings of the 2003 American Society for Engineering Education Annual Conference, Nashville, TN.

Perkins, D. (1997). Creativity's camel: The role of analogy in invention. In T. Ward, S. Smith, \& J. Vaid (Eds.), Creative thought (pp. 523-528). Washington, DC: American Psychological Association. 
Purcell, A. T., \& Gero, J. S. (1996). Design and other types of fixation. Design Studies, 17, 363-383.

Purcell, A. T., Williams, P., Gero, J. S., \& Colbron, B. (1993). Fixation effects: Do they exist in design problem-solving? Environment and Planning B: Planning and Design, 20, 333-345.

Richards, G. (1998). Stimulating creativity: Teaching engineers to be innovators. Proceedings of the Frontiers in Education Conference, 1034-1039.

Riesbeck, C. K., \& Schank, R. C. (1989). Inside case-based reasoning. Hillsdale, NJ: Lawrence Erlbaum Associates, Inc.

Rowe, P. (1987). Design thinking. Cambridge, MA: The MIT Press.

Sachs, A. (1999). Stuckness in the design studio. Design Studies, 20(2), 195-209.

Sheppard, S., Macatangay, K., Colby, A., \& Sullivan, W. (2009). Educating engineers: Design for the future of the field. San Francisco: Jossey-Bass.

Smith, G. F. (1998). Idea-generation techniques: A formulary of active ingredients. Journal of Creative Behavior, 32(2), 107-133.

Smith, S. M. (1995). Getting into and out of mental ruts: A theory of fixation, incubation and insight. In R. J. Sternberg \& J. E. Davidson (Eds.), The nature of insight (pp. 229-251). Cambridge, MA: MIT Press.

Terninko, J., Zusman, A., \& Zlotin, B. (1998). Systematic innovation, An introduction to TRIZ. Boca Raton: St Lucie Press.

Todd, R., Magleby, S., Sorensen, C., Swan, B., Anthony, D. (1995). A survey of capstone engineering courses in North America. Journal of Engineering Education, 84(2), 165-174.

Torrance, E. P. (1962). Guiding creative talent. Englewood Cliffs, NJ: Prentice Hall.

Treffinger, D., Young, G., Shelby, E., \& Shepardson, C. (2002). Assessing creativity: A guide for educators. Storrs, CT: The National Research Center on the Gifted and Talented.

Ullman, D., Dietterich, T., \& Stauffer, L. (1988). A model of the mechanical design process based on empirical data. AI in Engineering Design and Manufacturing, 2(1), 33-52.

Volkema, R. J. (1983). Problem formation in planning and design. Management Science, 29(6), 639-652.

von Oech, R. (2010). Creative Whack Pack Card Pack. Retrieved August 30, 2011, from http:// www.creativethink.com/products.html.

Yilmaz, S., Daly, S. R., Seifert, C. M., \& Gonzalez, R. (2010). A comparison of cognitive heuristics use between engineers and industrial designers. Proceedings of the 4 th International Conference on Design Computing and Cognition (DCC'10), Stuttgart, Germany.

Yilmaz, S., \& Seifert, C. M. (2009). Cognitive heuristics employed by design experts: A case study. Proceedings of the 4th International Conference of International Association of Society of Design Research (IASDR), Seoul, Korea.

Yilmaz, S., \& Seifert, C. M. (2010). Cognitive heuristics in design ideation. Proceedings of the 11th International Design Conference, Dubrovnik, Croatia.

Yilmaz, S., \& Seifert, C. M. (2011). Creativity through design heuristics: A case study of expert product design. Design Studies, 32(4), 384-415.

Yilmaz, S., Seifert, C. M., Christian, J. L., Daly, S. R., \& Gonzalez, R. (2012). Design heuristics observed in innovative products. Manuscipt. Iowa State University and University of Michigan.

Yilmaz, S., Seifert, C. M., \& Gonzalez, R. (2010). Cognitive heuristics in design: Instructional strategies to increase creativity in idea generation. Journal of Artificial Intelligence in Engineering Design and Manufacturing, 24, 335-355. 
Zwicky, F. (1969). Discovery, invention, research through the morphological approach. New York, NY: Macmillan.

\section{AUTHORS}

Shanna R. Daly is an assistant research scientist in engineering education at the University of Michigan, 210 Gorguze Family Laboratory, 2609 Draper Road, Ann Arbor, Michigan, 48109; srdaly@umich.edu.

Seda Yilmaz is an assistant professor of industrial design and human computer interaction at Iowa State University, 146 College of Design, Ames, Iowa, 50010; seda@iastate. edu.

James L. Christian is a graduate student in mechanical engineering at the Massachusetts Institute of Technology, 235 Albany Street, Cambridge, Massachusetts, 02139; jimc@mit.edu.

Colleen M. Seifert is a professor of psychology at the University of Michigan, 530 Church St., Ann Arbor, Michigan, 48109; seifert@umich.edu.

Richard Gonzalez is a professor of psychology, marketing, and statistics at the University of Michigan, 530 Church St., Ann Arbor, Michigan, 48109; gonzo@umich.edu. 